\title{
Survey
}

\section{Modelling suggests authentic leadership from managers influences structural empowerment, job satisfaction and self-rated performance among nurses}

\section{Jacqueline Leigh}

$10.1136 /$ eb-2013-101424

Department of Nursing, Midwifery and Social Work, University of Salford, Manchester, UK

Correspondence to: Dr Jacqueline Leigh Department of Nursing, Midwifery and Social Work, University of Salford, Frederick Road, Manchester M6 6PU, UK, J.A.Leigh4@salford.ac.uk

Commentary on: Wong CA, Laschinger HK. Authentic leadership, performance, and job satisfaction: the mediating role of empowerment. J Adv Nurs 2013;69:947-59

\section{Implications for practice and research}

- If more nurse managers/leaders are seen as authentic this will increase the number of nurses who perceive that they have access to empowerment structures in the workplace. This will increase job satisfaction and performance.

- The creation of future leadership development programmes should enhance the authentic leadership of nurse leaders.

- Future research should evaluate the impact of a multidimensional approach to leadership development on improving the culture of healthcare organisations.

\section{Context}

There is a growing body of evidence linking the transformation of healthcare services with an empowered workforce which is achieved in part through effective leadership. This study by Wong and colleagues correlates empowerment, job satisfaction and job performance with authentic leadership; an approach that focuses on whether the leader is genuine. The four key characteristics of the authentic leader are: selfawareness, internalised moral perspective, balanced processing and relational transparency. ${ }^{1}$

\section{Methods}

The purpose of the study was to use Avolio and colleagues' theory of authentic leadership to test a hypothesised model; linking the authentic leadership of managers with acute care nurses' perceptions of structural empowerment, performance and job satisfaction. ${ }^{2}$ The study used a non-experimental, predicted survey design that incorporated a range of measures such as the Authentic Leadership Questionnaire. Out of a sample 
of 600 registered nurses working in acute care teaching and community hospitals in Ontario, 280 completed the survey questionnaire (48\% response rate). Multiple statistical tests were applied to the data and this generated descriptive results and data for each of the applied measurements.

\section{Findings}

The average years of experience for the sample were 18.9 years. All component parts in the hypothesised model were reported as statistically significant. For example, authentic leadership had a statistically significant positive direct effect on structural empowerment, which in turn had a statistically significant direct effect on job satisfaction and performance. The findings suggest that the more authentic the leader is perceived to be, the more formal power nurses experience in their own role.

\section{Commentary}

This study focused on structural empowerment to evaluate the association between authentic leadership and job satisfaction and performance. Structural empowerment can be conceptualised as systems and processes in the workplace that enable the employee to accomplish their work in a meaningful way. ${ }^{3}$ These are wide ranging and include human and non-human resources such as working within a learning organisation and having access to information, support and feedback. This study further confirms the findings by Cummings et $a l^{4}$ whereby the leader being open, honest and transparent with one's own feelings, enhances nurses job satisfaction. Furthermore, Stanley ${ }^{5}$ introduces the concept of congruent leadership; whereby the personal qualities of the leader are used to enhance patient care.

The importance of this study to future leadership development is the recognition of the impact of the healthcare leader's behaviours on providing quality and safe patient care, achieved in part by increasing nurses' job performance and satisfaction. The application of the four components of authentic leadership seems to enhance the leader-follower relationship. Although caution needs to be taken for leadership developers who focus their development solely around the person and his/her personality. In reality, a multidimensional approach to leadership development is required to deliver the global healthcare agenda. This encompasses preparing the leader in the role and seeking an organisational leadership development approach that promotes the vision and corporate values of the organisation. Leadership skills include the need to drive through change and deal with complex leadership situations in innovative and creative ways. ${ }^{6}$ This multidimensional approach could offer the best platform for: increasing the healthcare leaders personal integrity as a leader; developing the skills to lead with emotional intelligence; and embedding the six Cs of nursing within the culture of the organisation: care, compassion, courage, commitment, communication and competency.

Competing interests None.

\section{References}

1. Northouse P. Leadership: theory and practice, 6th edn, London: Sage, 2013.

2. Avolio BJ, Gardner WL, Walumbwa FO, et al. Unlocking the mask: a look at the process by which authentic leaders impact follower attitudes and behaviours. Leadership Q 2004;15:801-23.

3. Kanter RM. Men and women of the corporation, 2nd edn., New York: Basic books, 1993.

4. Cummings GG, MacGregor T, Davey M, et al. Leadership styles and outcome patterns for the nursing workforce and work environment: a systematic review. Int J Nurs Stud 2010;47:363-85.

5. Stanley D. Recognizing and defining clinical nurse leaders. $\mathrm{Br}$ Nurs 2006;15:108-11.

6. Leigh JA, Rutherford J, Wild J, et al. The patchwork text assessment-an integral component of constructive alignment curriculum methodology to support healthcare leadership development. J Educ Train Stud 2013;1:139-50. 